\title{
Interactive comment on "The cryostratigraphy of the Yedoma cliff of Sobo-Sise Island (Lena Delta) reveals permafrost dynamics in the Central Laptev Sea coastal region during the last about 52 ka" by Sebastian Wetterich et al.
}

Anonymous Referee \#1

Received and published: 25 August 2020

Wetterich et al. present a comprehensive physical and geochemical characterisation of a Yedoma exposure on Sobo-Sise Island in the Lena Delta. Yedoma sections across the Siberian Arctic provide a unique window to look back on the Middle and Late Pleistocene and reconstruct environmental and climatic conditions based on a range of proxy indicators. This study complements previous studies of Yedoma exposures from the same region, but notably this study examines the Sobo-Sise section in very high stratigraphic/temporal detail compared to studies of other exposures. The authors discuss a number of sedimentological, cryological, isotopic and geochemical indicators to 
understand the environmental conditions associated with the formation of this deposit during Marine Isotope Stages 3, 2 and 1. Robust end-member mixing models are used to identify different sediment sources, and stable water isotopes of pore ice and wedge ice are used to understand the potential value of these different ice types as proxies for local climate and ice systematics. Largely I agree with the analysis and interpretations. The authors also identified chronological gaps in the record that are missing in other Yedoma sections from other sites, which provides clear evidence of a major change in regional environmental conditions that drive Yedoma accumulation. They speculate that two of these gaps may be related to major glacial-lake discharge events due to modified local drainage systems such that available source material of Yedoma accumulation was effectively impacted. It is an interesting, but still unproven point and the authors are careful to not over-interpret this. The paper itself is well written and clear. The methods and study design are scientifically sound. Overall I was impressed with the quality (and quantity) of results and discussion in this paper.

In my view, this paper is well-suited for publication in the Cryosphere. I only have some minor points that should be addressed prior to acceptance, as follows:

L141 - if available, please indicate somewhere what the elevation of river level is in m.a.s.I. L207 - "... not fully...' it is not clear what is meant here. Please clarify this part. L225 - "ballpark" please avoid this colloquialism. L411 - 'Unit', in reference to specific units, is a proper noun and should be capitalized. L456 - suggest using 'relict permafrost' instead of fossil permafrost L477 - This difference would be enhanced if differences in paleo-seawater were explicitly corrected for since mean ocean water during MIS 2 was enriched in heavy isotopologues compared to MIS 3 L506 - this is confusing since 'exceed' typically means values are 'more positive than'. Please use other words to clarify what is meant. L511 - please clarify what is meant. no need to describe the process in detail, but it should be clear what you are talking about. currently it is not clear. L529 - especially when paleo-seawater is considered, the difference is even less significant. L535-537 - following this sentence. "As such..."[please finish this thought]

Printer-friendly version

Discussion paper
Interactive

comment 
L625-626 - perhaps you can go one step further to discount direct erosion on the basis that such an event would likely remove tens of meters of sediment, and you are only missing $\sim 3.5 \mathrm{~m}$ given the mean accumulation rate.

Interactive comment on The Cryosphere Discuss., https://doi.org/10.5194/tc-2020-179, 2020. 